\title{
Production of DAPG and HCN by Pseudomonas sp. LBUM300 Contributes to the Biological Control of Bacterial Canker of Tomato
}

\author{
Carine Lanteigne, Vijay J. Gadkar, Thérèse Wallon, Amy Novinscak, and Martin Filion
}

Université de Moncton, Department of Biology, Moncton, NB, Canada, E1A 3E9.

Accepted for publication 30 May 2012.

\begin{abstract}
Lanteigne, C., Gadkar, V. J., Wallon, T., Novinscak, A., and Filion, M. 2012. Production of DAPG and HCN by Pseudomonas sp. LBUM300 contributes to the biological control of bacterial canker of tomato. Phytopathology 102:967-973.

Bacterial canker caused by Clavibacter michiganensis subsp. michiganensis is known to cause significant economic losses to tomato production worldwide. Biological control has been proposed as an alternative to current chemical containment methods, which are often inefficient and may leave adverse effects on the environment. However, only little headway has so far been made in developing biocontrol strategies against $C$. michiganensis subsp. michiganensis. To address this knowledge gap, we investigated the antagonistic capacity of PCA, produced by Pseudomonas sp. LBUM223, and DAPG and HCN, both produced by Pseudomonas sp. LBUM300, on C. michiganensis subsp.

michiganensis under in vitro and in planta conditions. Nonsynthesizing isogenic mutants of the producer strains were also developed to further dissect the role of each individual metabolite on C. michiganensis subsp. michiganensis biological control. Novel specific quantitative polymerase chain reaction TaqMan assays allowed quantification of $C$. michiganensis subsp. michiganensis in tomato plants and rhizospheric soil. Pseudomonas spp. LBUM223 and LBUM300 significantly repressed $C$. michiganensis subsp. michiganensis growth in vitro, while their respective nonproducing mutants showed less or no significant antagonistic activity. In planta, only Pseudomonas sp. LBUM300 was capable of significantly reducing disease development and $C$. michiganensis subsp. michiganensis rhizospheric population, suggesting that the production of both DAPG and $\mathrm{HCN}$ was involved. In summary, simultaneous DAPG/HCN production by Pseudomonas sp. LBUM300 shows great potential for controlling bacterial canker of tomato.
\end{abstract}

Bacterial canker of tomato caused by Clavibacter michiganensis subsp. michiganensis $(5,21)$ is considered the most important bacterial disease affecting tomato crops worldwide $(8,17)$. This phytopathogen infects host plants via roots or wounds and invades the xylem vessels, followed by a systemic infection of the host (9). No commercial tomato cultivar shows complete resistance to the disease (10) and progress towards breeding genetic resistant tomato lines has only been modest $(7,10)$.

Copper-based chemical treatments have traditionally been used in an attempt to control the disease $(12,31)$. More recently, plant activators for resistance induction (22) and biological control $(3,4,25,27,30,32-34)$ have also been proposed as control strategies. However, none of these approaches have so far proven to be successful for reliably and consistently controlling bacterial canker of tomato.

Pseudomonads are well characterized plant growth-promoting rhizobacteria (PGPR) that have long been recognized for their role in the natural suppression of different plant diseases $(11,15,19,29)$. One of the key biocontrol mechanisms used by pseudomonads is antibiosis (30). Among the different antimicrobial metabolites of interest for controlling plant pathogens, phenazine-1-carboxylic acid (PCA), 2,4-diacetylphloroglucinol (DAPG), and hydrogen cyanide ( $\mathrm{HCN}$ ) have been largely studied and characterized (11). Unfortunately, little is known about the potential of pseudomonads for controlling bacterial canker of tomato $(4,25)$. Furthermore, no study has, to our knowledge, specifically demonstrated the contribution of antimicrobial metabolite production by pseudomonads for controlling $C$. michiganensis subsp. michiganensis and preventing the development of the disease it causes.

Corresponding author: M. Filion; E-mail address: martin.filion@umoncton.ca

http://dx.doi.org/10.1094/PHYTO-11-11-0312

(c) 2012 The American Phytopathological Society
Two strains of Pseudomonas spp., namely LBUM223 and LBUM300, both known producers of PCA and DAPG/HCN, respectively, were used in this study. These strains have been previously isolated in our laboratory and characterized for their capacity at controlling certain plant diseases, namely common scab of potato caused by Streptomyces scabies (23) and Verticillium wilt of strawberry caused by Verticillium dahliae (18). The operons involved in PCA, DAPG, and HCN production have been sequenced, which has opened the way to perform mutagenesis of key biosynthetic genes, leading to mutants not producing the antimicrobial metabolites of interest. Such isogenic mutants are of high interest for inferring the contribution of specific antimicrobial metabolites to key biological functions such as biological control.

In this study, we evaluated the ability of Pseudomonas sp. LBUM223 and LBUM300, as well as their respective nonproducing mutants (LBUM223phz $\mathrm{C}^{-}$incapable of producing PCA, LBUM300phlD incapable of producing DAPG and LBUM300hcn $C^{-}$incapable of producing $\mathrm{HCN}$ ), to (i) repress the in vitro growth of $C$. michiganensis subsp. michiganensis; (ii) control the development of bacterial canker symptoms on tomato plants; (iii) modulate the population dynamics of C. michiganensis subsp. michiganensis in the rhizosphere; and (iv) in planta. The population dynamics of $C$. michiganensis subsp. michiganensis in the rhizosphere and in planta was studied using novel specific polymerase chain reaction PCR primers and a TaqMan probe, allowing the quantification of the highly specific pat-1 gene using qPCR assays.

\section{MATERIALS AND METHODS}

Bacterial strains and growth conditions. Pseudomonas spp. LBUM223 and LBUM300 were previously isolated from the rhizosphere of strawberry plants in Bouctouche, NB, Canada (18). 
These Pseudomonas strains were routinely grown at $25^{\circ} \mathrm{C}$ for approximately $24 \mathrm{~h}$ with continuous shaking in tryptic soy broth (TSB). The C. michiganensis subsp. michiganensis strain LMG 5644 (1982, B. Dhavantari, Canada) was obtained from the Microbiology Laboratorium of the University of Gent (Belgium) and routinely grown in Luria Bertani (LB) broth at $25^{\circ} \mathrm{C}$ for approximately $24 \mathrm{~h}$ with continuous shaking.

Site directed mutagenesis of $p h z C, h c n C$, and phlD in Pseudomonas strains. The PCA and DAPG/HCN synthesizing capacity of Pseudomonas spp. LBUM223 and LBUM300, respectively, was disrupted using the suicide plasmid pKNOCK-Gm ${ }^{\mathrm{r}}$ (2). The genes chosen for disruption were $p h z C$, phlD, and $h c n C$, which are part of the PCA, DAPG and HCN operons, respectively. These genes play a pivotal role in the biosynthesis of their respective antimicrobial compounds. The experimental procedure used for the targeted disruption of $p h z C$ has been described in details in StOnge et al. (23). A similar procedure was used for disrupting the phlD (GenBank accession no. DQ788986) and hcnC (GenBank accession no. DQ788980) genes which were previously sequenced from Pseudomonas sp. LBUM300 (Table 1 provides a list of the primers used). Screening of the clones obtained following mutagenesis was performed via PCR (Table 1) as well as assayed biochemically to further confirm the loss in production of DAPG and HCN. The DAPG and HCN production assays were performed as described by Zha et al. (35) and Sarniguet et al. (20), respectively. In each of these assays, the appropriate wildtype Pseudomonas spp. was used as a positive control. The mutant strains were routinely grown in TSB at $25^{\circ} \mathrm{C}$ for approximately $24 \mathrm{~h}$ with continuous shaking.

In vitro confrontational assays. In vitro confrontational inhibition assays were performed on petri plates using two different growth media, M6 (glucose [10 g], yeast extract [5 g], peptone [5 g], agar [15 g] in distilled water [1 liter] at $\mathrm{pH} 7.0$ ) and KB (14), one favoring the growth of $C$. michiganensis subsp. michiganensis and the other Pseudomonas spp., respectively. Two hundred microliters of $C$. michiganensis subsp. michiganensis log culture was spread onto the petri plates and allowed to dry. Afterwards, a 20- $\mu$ l spot of the appropriate Pseudomonas sp. (LBUM223, LBUM223phzC $C^{-}$LBUM300, LBUM300phlD ${ }^{-}$, LBUM300hcn $C^{-}$, or none-control) $\log$ culture was inoculated on the center of the plate and again allowed to dry. The plates were afterwards sealed, inverted, and incubated at $25^{\circ} \mathrm{C}$ for $62 \mathrm{~h}$ in the dark. The experiment consisted of four randomized blocks, each containing a total of 12 treatment combinations, for a total of 48 plates. This experiment was repeated twice.

Inhibition zones corresponding to the distance between the margin of the Pseudomonas spp. spot and the limits of C. michiganensis subsp. michiganensis's growth area were measured. Only complete inhibition zones (clear zones) were considered. The average of four random measurements $(\mathrm{cm})$ was calculated for each petri plate.

In planta assays. Seeds of Solanum lycopersicum 'Scotia' (Vesey's Seeds, York, Canada) were first germinated on watered compressed peat disks (Vesey's Seeds) and incubated for 14 days in a growth chamber (Conviron, Winnipeg, Canada) under controlled conditions $\left(12 \mathrm{~h}\right.$ light: $12 \mathrm{~h}$ dark photoperiod, $25^{\circ} \mathrm{C}$,
$80 \%$ humidity). Plantlets were then transplanted into 4-in. diameter pots filled with $300 \mathrm{~g}$ of nonsterile agricultural field soil collected in Bouctouche, NB, Canada. The soil was characterized as a gleyed podzolic gray luvisol, a subgroup of the Canadian System of Soil Classification (1), with a pH of 5.2, 62\% sand, $25 \%$ silt, $13 \%$ clay, and $2.6 \%$ organic matter. The soil was stored at $4{ }^{\circ} \mathrm{C}$ before use.

At transplantation, the root system of the plantlets was briefly dipped in one of the following Pseudomonas spp. solution (prepared in $0.9 \%$ saline water) at a concentration of $1 \times$ $10^{8}$ bacteria/ml: LBUM223, LBUM223phz $C^{-}$, LBUM300, LBUM300phlD ${ }^{-}$, LBUM300hcn $C^{-}$, or none-control. Following transplantation, an additional $5 \mathrm{ml}$ of the respective Pseudomonas spp. solution $\left(1 \times 10^{8}\right.$ bacteria/ml $)$ and $5 \mathrm{ml}$ of a $C$. michiganensis subsp. michiganensis solution $\left(2 \times 10^{9}\right.$ bacteria/ml or nonecontrol) were inoculated in the soil/root area of each plantlet. The plantlets were afterwards grown in a growth chamber (Conviron) $\left(16 \mathrm{~h}\right.$ light: $8 \mathrm{~h}$ dark photoperiod with alternating $25^{\circ} \mathrm{C}: 20^{\circ} \mathrm{C}$ thermoperiod, $100 \%$ humidity). The plants were watered daily or when needed.

The experimental set-up consisted of two harvesting dates (2 and 4 weeks postinoculation-destructive sampling), seven treatments (C. michiganensis subsp. michiganensis, C. michiganensis subsp. michiganensis + LBUM223, C. michiganensis subsp. michiganensis + LBUM223phzC $C^{-}$C. michiganensis subsp. michiganensis + LBUM300, C. michiganensis subsp. michiganensis + LBUM300phlD ${ }^{-}, C$. michiganensis subsp. michiganensis + LBUM300hcnC $C^{-}$, and control), and four replicates per time/treatment for a total of 56 samples. This experiment was repeated twice.

In planta assays: Disease severity. Four weeks postinoculation, disease symptoms were recorded using a 0 to 5 severity rating scale as previously described in Soylu et al. (22): 0 representing no visible symptoms, 1 representing marginal wilting of the leaves ( 1 to $10 \%$ ), 2 representing 11 to $25 \%$ of the leaves wilting, 3 representing 26 to $49 \%$ of the leaves wilting associated with chlorosis, 4 representing pronounced collapsing of the leaves (50 to $74 \%$ of the leaves wilting), and 5 representing $100 \%$ of the leaves wilting (dead plant).

In planta assays: Harvesting of the plants. After 2 and 4 weeks of growth postinoculation, four plants per treatment were harvested (destructive sampling). The rhizosphere soil and plants were immediately frozen in liquid nitrogen and stored at $-80^{\circ} \mathrm{C}$ until used. The rhizosphere soil was later lyophilized using a ModulyoD Freeze Dryer (Thermo Fisher Scientific, Waltham, MA).

Microbial DNA extraction from the stems and rhizosphere soil. Total DNA was extracted from $0.25 \mathrm{~g}$ of rhizosphere soil samples using the PowerSoil DNA Isolation kit (MoBio Laboratories, Carlsbad, CA) according to the manufacturer's recommendations with only one modification: tubes were shaken with a FastPrep FP120 (Thermo Fisher Scientific) for $30 \mathrm{~s}$ at 5.5 intensity instead of being vortexed for $10 \mathrm{~min}$.

Total DNA was also extracted from $0.1 \mathrm{~g}$ of stem samples crushed in liquid nitrogen using the DNeasy Plant Mini Kit (Qiagen, Mississauga, Canada) according to the manufacturer's

TABLE 1. Nucleotide sequences of the primers and TaqMan probe used in this study

\begin{tabular}{|c|c|c|c|}
\hline Target gene & Name & Sequence $\left(5^{\prime} \rightarrow 3^{\prime}\right)^{\mathrm{a}}$ & Product size (bp) \\
\hline$p h l D$ & $\begin{array}{l}\text { KNXh5 } \\
\text { KNXh6 }\end{array}$ & $\begin{array}{ll}\mathrm{F} & \text { GGAATTCCTCGAGATGATGCCCTCGCTGACA } \\
\mathrm{R} & \text { GGAATTCCTCGAGCCGGGTTCCAAGTCCAGT }\end{array}$ & 545 \\
\hline henC & $\begin{array}{l}\text { KNXh11 } \\
\text { KNXh12 }\end{array}$ & $\begin{array}{ll}\mathrm{F} & \text { GGAATTCCTCGAGAACGTCGGCATGGAGG } \\
\mathrm{R} & \text { GAATTCCTCGAGAACTTTAGCCCGGTCTCC }\end{array}$ & 417 \\
\hline pat-1 & $\begin{array}{l}\text { Cmm166F } \\
\text { Cmm227R } \\
\text { Cmm185 }\end{array}$ & $\begin{array}{ll}\mathrm{F} & \text { TCCGGGCGCTACTATGCA } \\
\mathrm{R} & \text { TGACTACAGCGACGAACAATATCC } \\
\mathrm{P} & \text { TTCATGTCGCGCATAAA }\end{array}$ & 62 \\
\hline
\end{tabular}

a Underlined nucleotides were added to the primers to confer recognition to XhoI. 
recommendations. For both rhizosphere soil and stem samples, DNA quantity and quality was evaluated using a NanoDrop ND1000 spectrophotometer (NanoDrop Technologies, Wilmington, $\mathrm{DE})$.

qPCR primers and probe design. The design of primers and a TaqMan probe for qPCR was performed using the PrimerExpress 3.0 software (Applied Biosystems, Foster City, CA) based on the pat-1 gene sequence of $C$. michiganensis subsp. michiganensis NCPPB382 (GenBank accession no. NC009479). The TaqMan probe was labeled with a 6-FAM reporter dye at the $5^{\prime}$ end and with a MGBNFQ quencher dye at the $3^{\prime}$ end and obtained from Applied Biosystems. The primers were custom synthesized by Integrated DNA Technologies (Coralville, IA). The specificity of the designed set was confirmed using the BLASTn search tool in the NCBI database and qPCR amplifications. The latter was performed on DNA extracted from nonsterile field soil samples inoculated and uninoculated with $C$. michiganensis subsp. michiganensis and/or with each of the wild-type and mutant Pseudomonas strains used in this study. The sequences of the primers and the probe used are listed in Table 1.

Standard curve for absolute quantification of $C$. michiganensis subsp. michiganensis. The pat-1 partial 62-bp qPCR amplicon was cloned into the TOPO-TA plasmid (Invitrogen, Burlington, Canada) for generating a standard curve as described earlier (6) using 10-fold dilutions of plasmidic DNA containing the partial pat- 1 gene fragment ranging from $8.3 \times 10^{0}$ to $8.3 \times$ $10^{6}$ copies. Plasmid copy number was quantified using a spectrophotometer (NanoDrop Technologies) and the gene copy number was calculated according to the molar mass derived from the plasmid and the amplicon length. Dilutions of the known concentration of plasmidic DNA were finally made to generate the standard curve.

qPCR assays for absolute quantification of $C$. michiganensis subsp. michiganensis in the rhizosphere soil and tomato stems. Quantitative PCR targeting $62 \mathrm{bp}$ of the pat-1 fragment was performed using an ABI7500 Thermocycler and the TaqMan PCR Core Reagent kit (Applied Biosystems). Each qPCR reaction mix contained $6 \mu \mathrm{l}$ of DNA (diluted 1 in 10 following extraction); $2.5 \mu \mathrm{l}(1 \times)$ of TaqMan buffer; $5.5 \mu \mathrm{l}(5.5 \mathrm{mmol} / \mathrm{liter})$ of $\mathrm{MgCl}_{2} ; 0.5 \mu \mathrm{l}(200 \mu \mathrm{mol} / \mathrm{liter})$ of (each) dATP, dCTP, and $\mathrm{dGTP} ; 0.5 \mu \mathrm{l}(400 \mu \mathrm{mol} / \mathrm{liter})$ of dUTP; $1 \mu \mathrm{l}$ (100 nmol/liter) of probe; $2.5 \mu \mathrm{l}(200 \mathrm{nmol} / \mathrm{liter})$ of both primers; $0.25 \mu \mathrm{l}(0.01 \mathrm{U} / \mu \mathrm{l})$ of AmpErase uracil $N$-glycosylase; $0.125 \mu \mathrm{l}(0.025 \mathrm{U} / \mu \mathrm{l})$ of AmpliTaq Gold DNA polymerase; and $2.625 \mu \mathrm{l}$ of sterile $\mathrm{ddH}_{2} \mathrm{O}$ (Ambion), for a total volume of $25 \mu \mathrm{l}$. Negative control reactions were performed during each qPCR run by replacing DNA by sterile $\mathrm{ddH}_{2} \mathrm{O}$. Cycling conditions were: $50^{\circ} \mathrm{C}$ for $2 \mathrm{~min} ; 95^{\circ} \mathrm{C}$ for $10 \mathrm{~min}$; then 50 cycles of $95^{\circ} \mathrm{C}$ for $15 \mathrm{~s}$ and $60^{\circ} \mathrm{C}$ for $1 \mathrm{~min}$. All qPCR reactions were replicated three times.

Statistical analysis. Statistical analyses were performed using the SAS Statistical Software version 9.2 (SAS Institute Inc., 1992). Mixed ANOVAs were performed using the MIXED procedure on the inhibition zones and qPCR data (random variables: biological replicates and replications of the experiments; fixed variable: treatments). To meet the requirements of the tests, inhibition zones and qPCR data were rank-transformed and square-root-transformed, respectively. For the inhibition zones, a posteriori comparisons of the means between treatment levels of each growth media were carried out using Tukey-Kramer honestly significant differences tests at a 5\% level of significance, whereas a priori contrasts were performed on the qPCR data between appropriate treatments for each sampling date. Multinomial regression analyses were performed on the symptoms data using the GENMOD procedure with a priori contrasts between the appropriate treatments. Finally, a Spearman's correlation analysis was performed between the quantified stem population of $C$. michiganensis subsp. michiganensis and the symptoms observed at week four.

\section{RESULTS}

Production of isogenic mutant strains. The pKNOCK-Gm ${ }^{\mathrm{r}}$ based targeted gene disruption procedure was used and several clones of Pseudomonas sp. LBUM300, which had an insertion in the $p h l D$ and $h c n C$ target sites, were identified using PCR. Using biochemical tests designed to assay for the production of DAPG and $\mathrm{HCN}$, clones were identified (designated LBUM300phlD and LBUM300hcnC $C^{-}$) which were fully impaired in their ability to synthesize the target antimicrobial compounds (data not shown).

In vitro inhibition assays. Both Pseudomonas spp. LBUM223 and LBUM300 significantly repressed the growth of $C$. michiganensis subsp. michiganensis, while all respective mutants showed less or no efficiency. As shown in Figure 1, the growth inhibition of $C$. michiganensis subsp. michiganensis caused by Pseudomonas sp. LBUM223 was significantly larger $(P<0.05)$ than the inhibition caused by Pseudomonas sp. LBUM223phz $C^{-}$ on both M6 and KB media. The growth repression caused by Pseudomonas sp. LBUM300 was also significantly greater $(P<$ $0.05)$ than the one caused by Pseudomonas sp. LBUM300phlD on M6 and LBUM300hcnC $C^{-}$on KB.

Disease symptoms. No disease symptoms were found on control plants while typical symptoms of bacterial canker were observed on $C$. michiganensis subsp. michiganensis-inoculated plants (Fig. 2). A significant decrease $(P<0.05)$ in disease severity was observed when plants inoculated with the pathogen were co-inoculated with Pseudomonas sp. LBUM300. No other significant decrease in disease severity was obtained when tomato plants were inoculated with the pathogen and either Pseudomonas sp. LBUM223 or any of the mutant strains under study.

Primer specificity and amplification efficiency. The PCR amplification of DNA extracted from nonsterile soil inoculated with $C$. michiganensis subsp. michiganensis generated a single band of the appropriate size when run on conventional agarose gel electrophoresis, while no amplification products were obtained from DNA extracted from uninoculated soil (data not shown). A linear relation was observed between log copy numbers of the

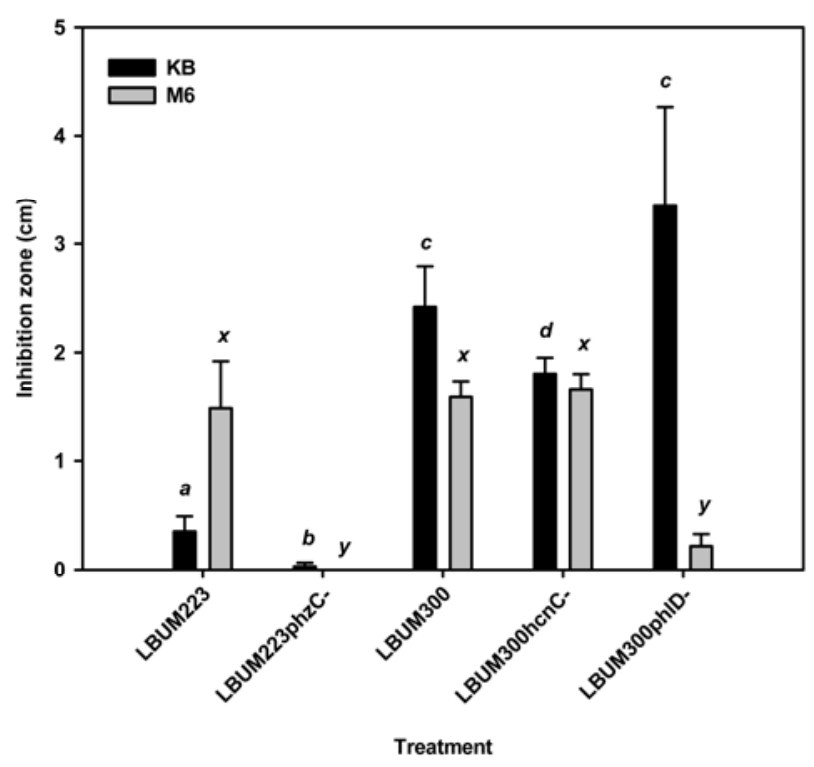

Fig. 1. Net average of the inhibition zones (centimeters) from in vitro confrontational assays between Clavibacter michiganensis subsp. michiganensis and Pseudomonas sp. LBUM223, LBUM223phzC $C^{\leftarrow}$, LBUM300, LBUM300hcnC ${ }^{\complement}$, and LBUM300phlD ${ }^{-}$performed on $\mathrm{KB}$ and M6 culture media. Bars within a compared group (KB or M6) showing different letters are significantly different according to mixed analyses of variance using a posteriori Tukey-Kramer honestly significant difference tests $(P<0.05)$. Error bars are standard error of the mean. 
cloned partial pat- 1 fragment and $\mathrm{qPCR}$ crossing points $\left(R^{2}=\right.$ 0.998 to 1.000 ) with an efficiency ranging from 95 to $105 \%$.

C. michiganensis subsp. michiganensis population in the rhizosphere. pat-1 gene fragment copy numbers detected in the rhizosphere soil via qPCR was transformed in absolute gene copy numbers to represent $C$. michiganensis subsp. michiganensis population per gram of soil. As shown in Figure 3, at 2 weeks postinoculation, the presence of $C$. michiganensis subsp. michiganensis was significantly reduced $(P<0.05)$ when Pseudomonas sp. LBUM300 was co-inoculated as opposed to when the pathogen was inoculated alone. No other significant differences in

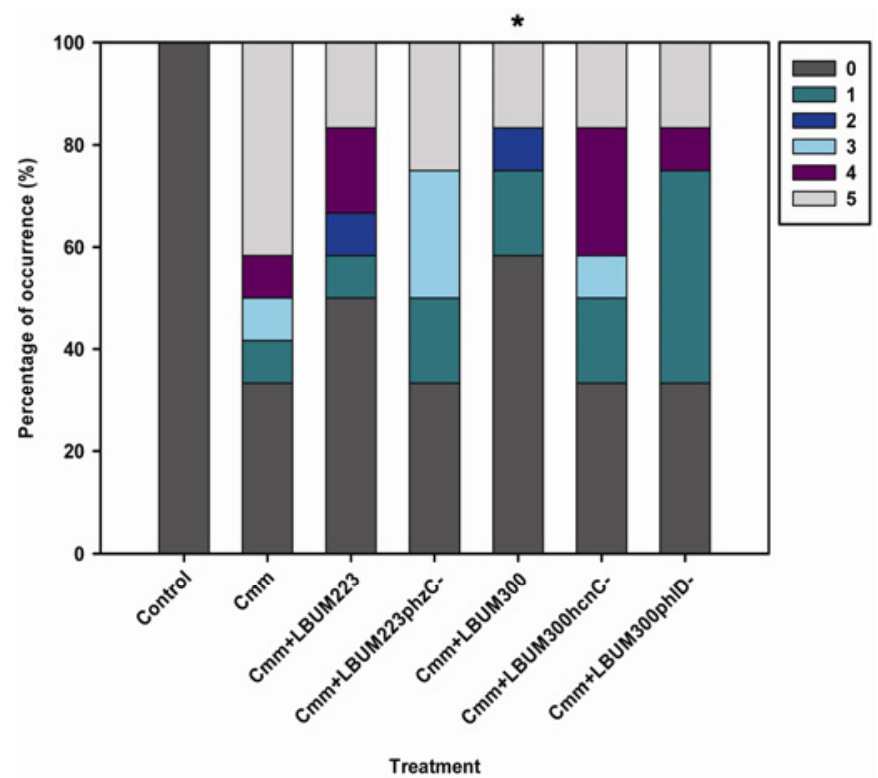

Fig. 2. Occurrence of bacterial wilt and canker disease symptoms on treated tomato plants using a severity scale of 0 to $5(0=$ no symptoms; $1=$ marginal wilting of the leaves [ 1 to $10 \%$ ]; $2=11$ to $25 \%$ of the leaves wilting; $3=26$ to $49 \%$ of the leaves showing wilting associated with chlorosis; $4=$ pronounced leaf collapse with 50 to $74 \%$ of the leaves wilting; and $5=$ total of the leaves wilting, dead plant). All treatments are significantly different from the control treatment. Treatment indicated with an asterisk is significantly different than the treatment inoculated with the pathogen only (Clavibacter michiganensis subsp. michiganensis $[\mathrm{Cmm}])(P<0.05)$.

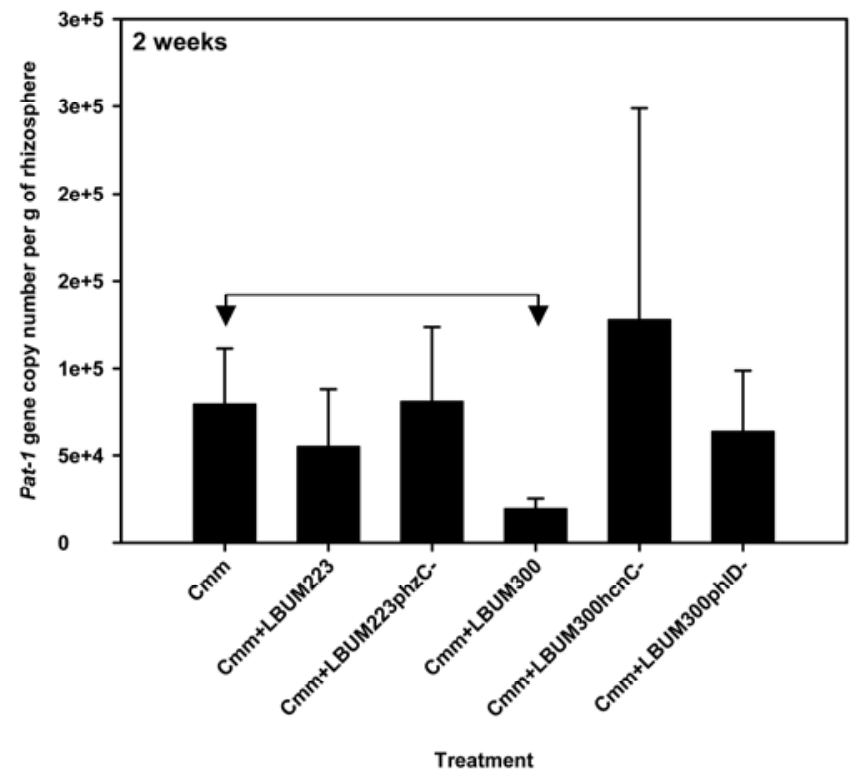

C. michiganensis subsp. michiganensis populations were detected at 2 weeks postinoculation. At 4 weeks postinoculation (Fig. 3), no significant impact on $C$. michiganensis subsp. michiganensis was detected, although a similar trend to the one observed at 2 weeks postinoculation was detected.

C. michiganensis subsp. michiganensis population in the stems. pat-1 gene fragment copy numbers detected in tomato stems via qPCR were transformed in absolute gene copy numbers to represent $C$. michiganensis subsp. michiganensis populations per gram of stem. No significant reduction of $C$. michiganensis subsp. michiganensis population was observed at 2 or 4 weeks postinoculation when plants were co-inoculated with Pseudomonas wild-type or mutant strains (Fig. 4).

Correlation between $C$. michiganensis subsp. michiganensis population in the stem and disease severity symptoms. $C$. michiganensis subsp. michiganensis population in the stems of tomato plants inoculated with the pathogen at 4 weeks postinoculation was positively correlated to the disease symptoms development observed ( $r=0.67 ; P<0.05$; Fig. 5).

\section{DISCUSSION}

In this study, two antimicrobial metabolite-producing Pseudomonas spp., as well as their respective nonproducing mutant strains, were studied for their capacity at controlling bacterial canker of tomato and populations of $C$. michiganensis subsp. michiganensis under in vitro and in planta conditions.

Under in vitro conditions, the growth of $C$. michiganensis subsp. michiganensis was repressed by both Pseudomonas spp. LBUM223 and LBUM300 while their respective mutant strains caused no or mostly smaller inhibition zones, suggesting that the production of PCA, DAPG, and HCN all contributed to control the growth of the pathogen. Interestingly, media composition altered the pathogen growth inhibition observed. For example, on M6 medium, loss of DAPG production in Pseudomonas sp. LBUM300phlD ${ }^{-}$reduced the growth inhibition of the pathogen when compared to wild-type LBUM300, an effect not observed on the KB medium. The same was also true for Pseudomonas sp. LBUM300hcnC $C^{-}$where pathogen growth inhibition was reduced on KB but not on M6. Similar results have been reported in other in vitro systems and it has previously been shown that various physiological factors like nutrients, $\mathrm{pH}$, and temperature may affect the production of antimicrobial metabolites by biocontrol

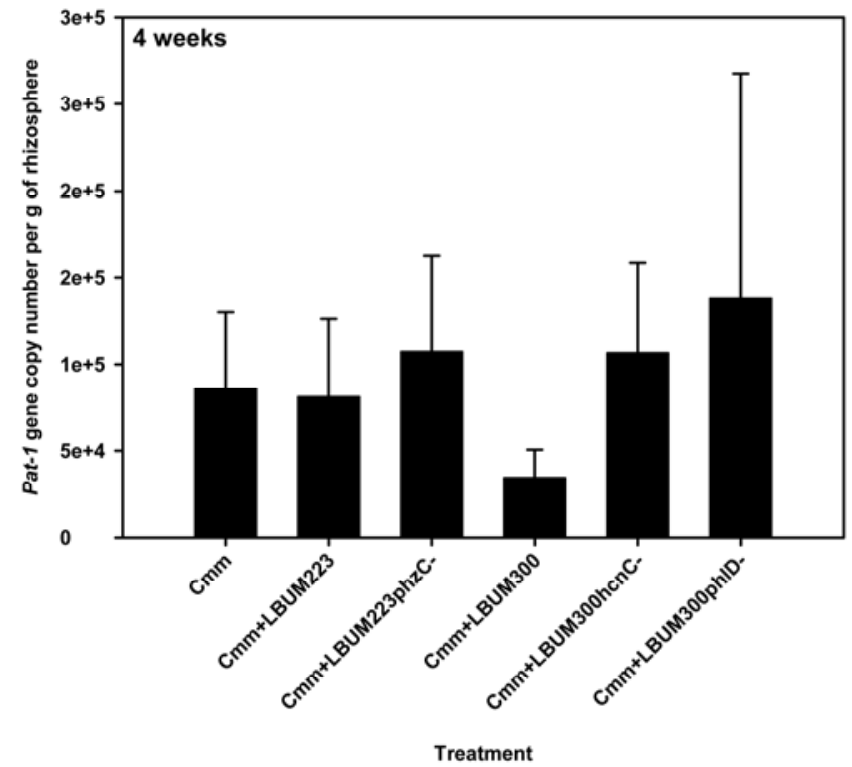

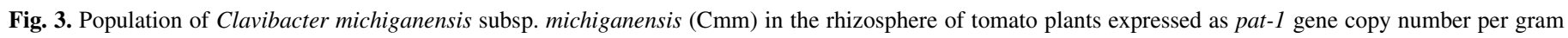
of soil. Treatments under the horizontal line are significantly different $(P<0.05)$. Error bars are standard error of the mean. 
agents $(13,24,26,28)$. More specifically, van Rij et al. (28) showed that production of phenazine-1-carboxamide $(\mathrm{PCN})$ by a strain of $P$. chlororaphis was influenced by different nutrient sources, including carbon and amino acids amongst others. The ability of Pseudomonas spp. LBUM223 and LBUM300 to repress pathogen growth is not surprising and has previously been reported in other in vitro systems, where LBUM300 inhibited the growth of Verticillium dahlia and Phytophthora cactorum (18) and LBUM223, the growth of Streptomyces scabies (23). The study by St-Onge et al. (23) was interesting as they were able to show a direct link between the pathogen growth inhibition and the production of PCA by Pseudomonas sp. LBUM223. However, to the best of our knowledge, this is the first in vitro demonstration of the contribution of PCA, DAPG, and HCN in controlling the growth of $C$. michiganensis subsp. michiganensis. A few other studies also looked at controlling $C$. michiganensis subsp. michiganensis in vitro using Pseudomonas spp. and other antagonistic microorganisms (4) including Streptomyces spp. (33), but no demonstration of the potential mechanisms involved, as it is reported in this study using isogenic mutant strains, was provided.

Under in planta conditions, only Pseudomonas sp. LBUM300 was capable of reducing bacterial canker disease development. Four weeks following inoculation of the plants, disease symptoms were significantly reduced in the Pseudomonas sp. LBUM300 inoculated treatment, while inoculation with Pseudomonas sp. LBUM300 phlD $D^{-}$or $h c n C^{-}$could not significantly reduce the symptoms observed. Again, this suggests that the production of both DAPG and HCN is required for symptom reduction. Surprisingly, Pseudomonas sp. LBUM223, which was capable of reducing $C$. michiganensis subsp. michiganensis growth under in vitro conditions, was incapable of reducing disease development under in planta conditions. The lack of congruity in results could be due to the drastic difference in these two experimental setups (in vitro versus soil). This variation is most likely attributed to the complex conditions of natural soils which dampen the functional efficacy of the target biocontrol bacterium.

A few other studies have also evaluated potential biocontrol strains and products against bacterial canker disease development. For example, Boudyach et al. (4) showed that three strains, including two fluorescent pseudomonads isolated from the rhizoplane, were able to significantly reduce the development of disease symptoms on tomato seedlings by seed and root treatment. Umesha (25) also showed that tomato canker incidence could be reduced by $P$. fluorescens seed treatments. Streptomyces spp., lysosyme, and available commercial biocontrol products have also showed positive results $(27,33)$. However, to the best of our knowledge, the impact of the production of secondary metabolites such as DAPG and HCN on bacterial canker disease symptom development had never been reported before.

In this study, a novel TaqMan qPCR assay was developed to quantify $C$. michiganensis subsp. michiganensis populations in rhizospheric soil and in planta. The functioning of the pat- 1 gene has earlier been shown to be directly responsible for the development of the wilting symptoms (16) and therefore, made it an attractive candidate marker for gene-based detection of $C$. michiganensis subsp. michiganensis. Similarly to what was observed for disease symptoms development, only Pseudomonas sp. LBUM300 significantly reduced the population of $C$. michiganensis subsp. michiganensis in the rhizosphere at 2 weeks

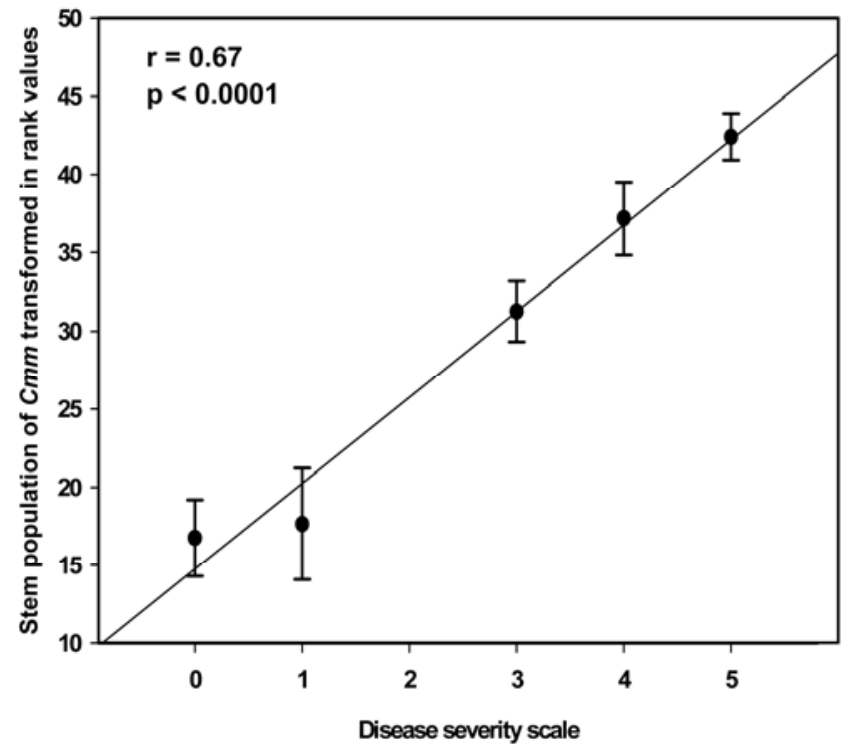

Fig. 5. Correlation between population of Clavibacter michiganensis subsp. michiganensis $(\mathrm{Cmm})$ in the stem of tomato plants and bacterial canker symptoms observed at 4 weeks postinoculation. Error bars are standard error of the mean.
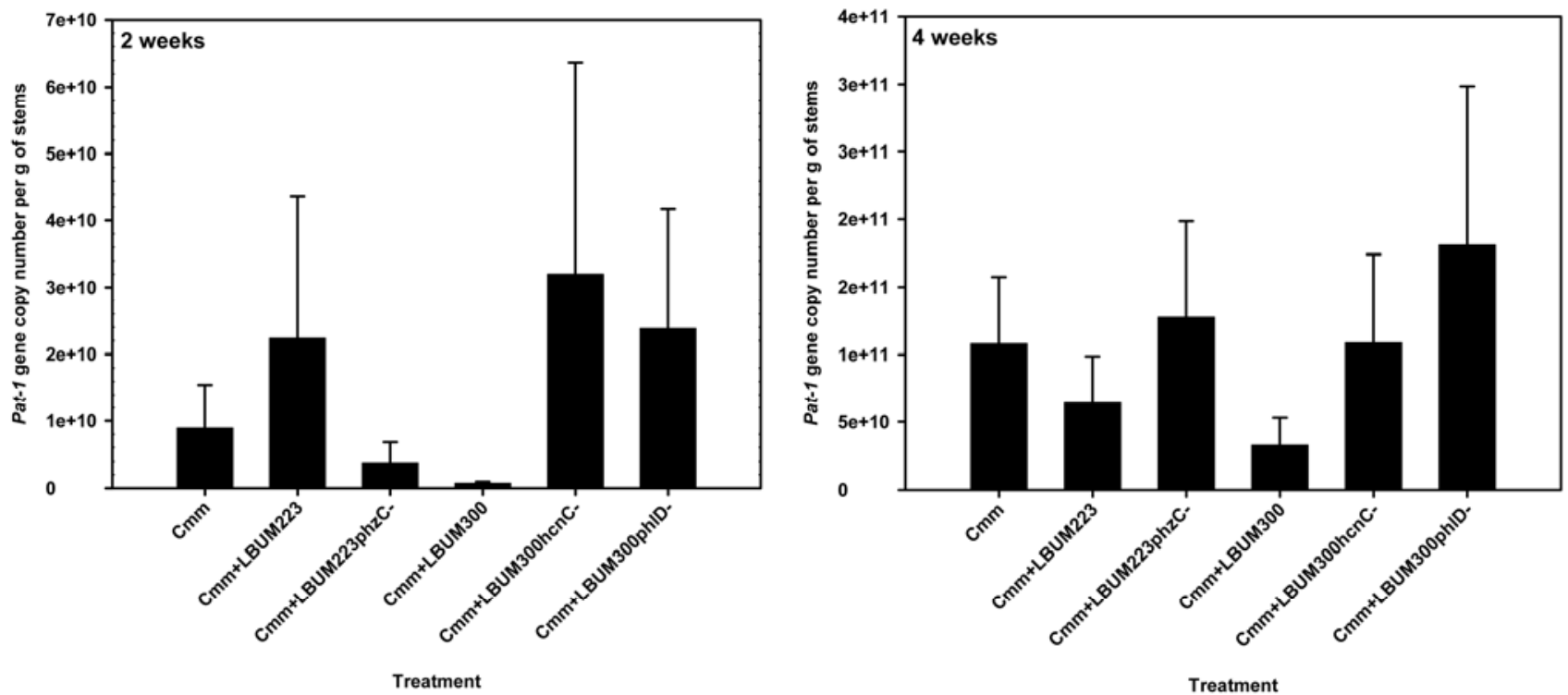

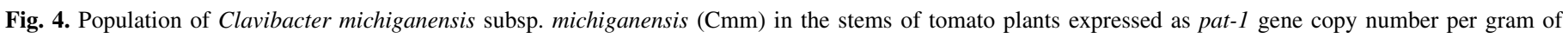
stem. No significant differences between treatments were found. Error bars are standard error of the mean. 
postinoculation. Although the significant reduction observed at 2 weeks postinoculation was not observed at 4 weeks, a similar trend was observed. Again, inoculation with Pseudomonas spp. LBUM300phlD ${ }^{-}$or LBUM300hcn $C^{-}$did not affect the growth of C. michiganensis subsp. michiganensis, suggesting that the simultaneous production of both DAPG and HCN is also involved in the pathogen population reduction observed. As C. michiganensis subsp. michiganensis can survive on plant debris in association with soil and spread through root wounds, it is therefore interesting that its population can be reduced by DAPG and HCN producing Pseudomonas sp. LBUM300 before it can enter the plant's vascular system.

Surprisingly, the population of C. michiganensis subsp. michiganensis found in tomato stems was not significantly affected by any Pseudomonas spp. inoculation treatments. As stem populations of vascular pathogens such as $C$. michiganensis subsp. michiganensis are more likely to vary drastically in relation to disease development stages, and that inevitably all biological replicates for a given inoculation treatment might not be exactly at the same disease developmental stage at the same moment, a high level of variation was observed. This is why we also evaluated the correlation that might exist between disease symptoms and $C$. michiganensis subsp. michiganensis populations in tomato stems. A strong positive correlation $(r=0.67 ; P<$ 0.0001 ) was observed, suggesting that the severity of the symptoms vary in accordance to stem populations of $C$. michiganensis subsp. michiganensis.

In this study, we have identified DAPG and HCN as the compounds likely responsible for the ability of Pseudomonas sp. LBUM300 to limit the growth of $C$. michiganensis subsp. michiganensis in vitro and to control the development of bacterial canker of tomato under soil conditions. Optimization of inoculum concentration, formulation and validation of the biological control activity of Pseudomonas sp. LBUM300 under large-scale greenhouse and field conditions will represent the next steps towards the implementation of a reliable biological control strategy.

\section{ACKNOWLEDGMENTS}

We thank T. Arseneault (Université de Moncton) for technical assistance; G. Moreau (Université de Moncton) for his statistical insight; and I. Oresnik (University of Manitoba, Winnipeg, MB, Canada) and N. Hironori (Genetic Strain Research Center, National Institute of Genetics, Mishima, Shizuoka, Japan) for providing the pKNOCK-Gm ${ }^{\mathrm{r}}$ plasmid vector and the $E$. coli $\mathrm{S} 17-1 / \lambda_{\text {pir }}$ strain, respectively. This study was supported by a Natural Sciences and Engineering Research Council of Canada (NSERC) grant to M. Filion.

\section{LITERATURE CITED}

1. Agriculture and Agri-Food Canada. 1998. The Canadian System of Soil Classification. NRC Research Press, Ottawa, Canada.

2. Alexeyev, M. F. 1999. The pKNOCK series of broad-host-range mobilizable suicide vectors for gene knockout and targeted DNA insertion into the chromosome of Gram-negative bacteria. BioTechniques 26:824828 .

3. Amkraz, N., Boudyach, E., Boubaker, H., Bouizgarne, B., and Ait Ben Aoumar, A. 2010. Screening for fluorescent pseudomonads, isolated from the rhizosphere of tomato, for antagonistic activity toward Clavibacter michiganensis subsp. michiganensis. World J. Microbiol. Biotechnol. 26: 1059-1065.

4. Boudyach, E. H., Fatmi, M., Akhayat, O., Benizri, E., and Aoumar, A. A. B. 2001. Selection of antagonistic bacteria of Clavibacter michiganensis subsp. michiganensis and evaluation of their efficiency against bacterial canker of tomato. Biocontrol Sci. Technol. 11:141-149.

5. Davis, M. J., Gillaspie, A. G., Jr., Vidaver, A. K., and Harris, R. W. 1984. Clavibacter: A new genus containing some phytopathogenic coryneform bacteria, including Clavibacter xyli subsp. xyli sp. nov., subsp. nov. and Clavibacter xyli subsp. cynodontis subsp. nov., pathogens that cause ratoon stunting disease of sugarcane and bermudagrass stunting disease. Int. J. Syst. Bacteriol. 34:107-117.

6. DeCoste, N. J., Gadkar, V. J., and Filion, M. 2010. Verticillium dahliae alters Pseudomonas spp. populations and $\mathrm{HCN}$ gene expression in the rhizosphere of strawberry. Can. J. Microbiol. 56:906-915.

7. de León, L., Siverio, F., López, M. M., and Rodríguez, A. 2008. Comparative efficiency of chemical compounds for in vitro and in vivo activity against Clavibacter michiganensis subsp. michiganensis, the causal agent of tomato bacterial canker. Crop Prot. 27:1277-1283.

8. de Léon, L., Siverio, F., López, M. M., and Rodríguez, A. 2011. Clavibacter michiganensis subsp. michiganensis, a seedborne tomato pathogen: Healthy seeds are still the goal. Plant Dis. 95:1328-1338.

9. Eichenlaub, R., Gartemann, K.-H., and Burger, A. 2006. Clavibacter michiganensis, a group of Gram-positive phytopathogenic bacteria. Pages 385-421 in: Plant-Associated Bacteria. S. S. Gnanamanickam, ed. Springer, Dordrecht, The Netherlands.

10. Gleason, M. L., Gitaitis, R. D., and Ricker, M. D. 1993. Recent progress in understanding and controlling bacterial canker of tomato in eastern North America. Plant Dis. 77:1069-1076.

11. Haas, D., and Defago, G. 2005. Biological control of soil-borne pathogens by fluorescent pseudomonads. Nat. Rev. Microbiol. 3:307-319.

12. Hausbeck, M. K., Bell, J., Medina-Mora, C., Podolsky, R., and Fulbright, D. W. 2000. Effect of bactericides on population sizes and spread of Clavibacter michiganensis subsp. michiganensis on tomatoes in the greenhouse and on disease development and crop yield in the field. Phytopathology 90:38-44.

13. Jayaswal, R. K., Fernandez, M. A., and Schroeder, R. G., III. 1990. Isolation and characterization of a Pseudomonas strain that restricts growth of various phytopathogenic fungi. Appl. Environ. Microbiol. 56:10531058.

14. King, E., Ward, M., and Raney, D. 1954. Two simple media for the demonstration of pyocyanin and fluorescin. J. Lab. Clin. Med. 44:301-307.

15. Maurhofer, M., Baehler, E., Notz, R., Martinez, V., and Keel, C. 2004. Cross talk between 2,4-diacetylphloroglucinol-producing biocontrol pseudomonads on wheat roots. Appl. Environ. Microbiol. 70:1990-1998.

16. Meletzus, D., Bermphol, A., Dreier, J., and Eichenlaub, R. 1993. Evidence for plasmid-encoded virulence factors in the phytopathogenic bacterium Clavibacter michiganensis subsp. michiganensis NCPPB382. J. Bacteriol. 175:2131-2136.

17. OEPP/EPPO. 2005. Clavibacter michiganensis subsp. michiganensis. OEPP-EPPO Bull. 35:275-283.

18. Paulin, M. M., Novinscak, A., St-Arnaud, M., Goyer, C., DeCoste, N. J., Privé, J.-P., Owen, J., and Filion, M. 2009. Transcriptional activity of antifungal metabolite-encoding genes phlD and hcnBC in Pseudomonas spp. using qRT-PCR. FEMS Microbiol. Ecol. 68:212-222.

19. Raaijmakers, J. M., Vlami, M., and de Souza, J. T. 2002. Antibiotic production by bacterial biocontrol agents. Antonie van Leeuwenhoek 81:537547.

20. Sarniguet, A., Lucas, P., Lucas, M., and Samson, R. 1992. Soil conduciveness to take-all of wheat: Influence of the nitrogen fertilizers on the structure of populations of fluorescent pseudomonads. Plant Soil 145:29-36.

21. Smith, E. F. 1910. A new tomato disease of economic importance. Science 31:790-799

22. Soylu, S., Baysal, Ö., and Soyle, E. M. 2003. Induction of disease resistance by the plant activator, acibenzolar-S-methyl (ASM), against bacterial canker (Clavibacter michiganensis subsp. michiganensis) in tomato seedlings. Plant Sci. 165:1069-1075.

23. St-Onge, R., Gadkar, V. J., Arseneault, T., Goyer, C., and Filion, M. 2011. The ability of Pseudomonas sp. LBUM 223 to produce phenazine-1carboxylic acid affects the growth of Streptomyces scabies, the expression of thaxtomin biosynthesis genes and the biological control potential against common scab of potato. FEMS Microbiol. Ecol. 75:173-183.

24. Trivedi, P., Pandey, A., and Palni, L. M. S. 2008. In vitro evaluation of antagonistic properties of Pseudomonas corrugata. Microbiol. Res. 163: 329-336.

25. Umesha, S. 2006. Occurrence of bacterial canker in tomato fields of Karnataka and effect of biological seed treatment on disease incidence. Crop Prot. 25:375-381.

26. Upadhyay, R. S., Visintin, L., and Jayaswal, R. K. 1991. Environmental factors affecting the antagonism of Pseudomonas cepacia against Trichoderma viride. Can. J. Microbiol. 37:880-884.

27. Utkhede, R., and Koch, C. 2004. Biological treatments to control bacterial canker of greenhouse tomatoes. BioControl 49:305-313.

28. van Rij, E. T., Wesselink, M., Chin-A-Woeng, T. F. C., Bloemberg, G. V., and Lugtenberg, B. J. J. 2004. Influence of environmental conditions on the production of phenazine-1-carboxamide by Pseudomonas chlororaphis PCL1391. Mol. Plant-Microbe Interact. 17:557-566.

29. Weller, D. M., Raaijmakers, J. M., McSpadden Gardener, B. B., and Thomashow, L. S. 2002. Microbial populations responsible for specific soil suppressiveness to plant pathogens. Annu. Rev. Phytopathol. 40:309348.

30. Weller, D. M., and Thomashow, L. S. 1993. Use of rhizobacteria for 
biocontrol. Curr. Opin. Biotechnol. 4:306-311.

31. Werner, N. A., Fulbright, D. W., Podolsky, R., Bell, J., and Hausbeck, M. K. 2002. Limiting populations and spread of Clavibacter michiganensis subsp. michiganensis on seedling tomatoes in the greenhouse. Plant Dis. 86:535-542.

32. Yogev, A., Raviv, M., Kritzman, G., Hadar, Y., Cohen, R., and Kirshner, B. 2009. Suppression of bacterial canker of tomato by composts. Crop Prot. 28:97-103.

33. Yuan, H.-p., Min, H., Lv, Z.-m., and Li, Z.-m. 2009. Antimicrobial activity of isolate HL-12 against Clavibacter michiganensis subsp. michiganensis in the presence of cadmium. Ecotoxicology 18:447-454.

34. Zanon, M. J., and Jorda, C. 2008. Eradication of Clavibacter michiganensis subsp. michiganensis by incorporating fresh crop debris into soil: Preliminary evaluations under controlled conditions. Crop Prot. 27:1511-1518.

35. Zha, W., Rubin-Pitel, S. B., and Zhao, H. 2006. Characterization of the substrate specificity of PhlD, a type III polyketide synthase from Pseudomonas fluorescens. J. Biol. Chem. 281:32036-32047. 